\title{
Damage Identification in 2D Structures Through Static Response
}

\author{
S.I. Robles ${ }^{1}$, N.F. Ortega*, ${ }^{* 1}$ and C.J. Orbanich ${ }^{1,2}$ \\ ${ }^{1}$ Engineering Department, Universidad Nacional del Sur, Bahía Blanca, Argentina and ${ }^{2}$ CONICET, Argentina
}

\begin{abstract}
The local stiffness reduction produced by cracks change the static and dynamic behavior of the structural elements and, by examining this change, crack position and magnitude can be identified. This paper presents a methodology which aim is the detection, location and quantification of the damage through the values of vertical displacements, produced by static loads. With the purpose of establishing the precision of the results obtained in planar structures, numerical simulations were made, analyzing them with the Finite Element Method. Furthermore, two techniques for the detection and damage location are presented. The first one is related to the displacement variation in a damaged structure in relation to the same structure without damage. The second technique is based on the elastic curvature which is computed by means of the Finite Differences Method. The techniques presented are versatile tools, of easy application at work, for structural damage identification.
\end{abstract}

\section{INTRODUCTION}

A structure may be damaged because of accidental overloads which exceed the bearing capacity, change or deterioration of its physical or mechanical properties, structural aging and environmental conditions, among others. With the purpose of detecting possible structural damages at an early stage, a lot of investigators have developed evaluation methods in order to know the elements conditions.

The interest, as regards certain types of structures, is to obtain a technique which allows for a continuous monitoring of the structure integrity. Among the non-destructive methods of damage identification are those which consider the changes in the dynamic response of the structure, i.e. natural frequencies, mode shapes, etc. These have been treated by several investigators so that there is a vast collection of publications in relation to this topic [1-8]. In comparison, there are few publications about damage identification, based on structure static response [9-14].

It is necessary to take into account that a crack in a structural element produces local changes to its stiffness. These changes are translated as variations in the static and dynamic behavior of the structural element. As regards the dynamic response, for instance is measured is the relative changes in frequencies, modal shape or response in frequencies, whereas in static responses, vertical displacements variations and/or deformations are measured. One method could be more convenient than another, and in some cases, complementary [15], depending on the analyzed structure and on the equipment availability to make the measurements in situ.

Non destructive tests in dynamic regime provide, in general, a large number of information with respect to static tests and, furthermore, since they can be easily carried out without interrupting the operation of a system, they are profitably repeatable during service. However, in cases of simple

*Address correspondence to this author at the Engineering Department, Universidad Nacional del Sur, Bahía Blanca, Argentina;

E-mail:nfortega@criba.edu.ar structural system, such as straight beams, subject to damage, static tests are easily executable and provide additional information to dynamic identification without any introduction of uncertainties due to inertia distribution and damping ratios [16]. Furthermore the basic equipment cost to make static tests is lower than corresponding to dynamic tests

It is necessary to mention that a damage identification algorithm includes four different analysis stages: damage detection, location, quantification and finally, the prediction of the remaining service life and/or residual resistance of the structure.

The application of a damage identification methodology is presented in this work, based on the static response (vertical displacements) of steel linear structures such as beams, reinforced concrete frames, and so analyzing the three first stages: detection, location and quantification of structural damage.

\section{DETECTION, LOCATION AND QUANTIFICATION OF DAMAGE}

As it was mentioned in the introduction, a damaged structure has less stiffness than a similar structure without damage. This can be seen in the static response, i.e. through the displacements as well as through the deformations produced by acting loads.

The displacements and deformations of a structure are related to its geometry, the mechanical properties of the material and of the acting loads. The damage can be due to a change in its geometry or a change in the mechanical properties of the material. Different methods of detection and damage location in the structures are compared in this work. They are based on the analysis of their static response. A method which allows damage quantification is also presented here.

Representative models of the structure were made, with and without damage, of simply supported beam, cantilever beam and bi-articulated frame. These were analyzed by (Algor 120) [17], software which uses the Finite Elements Method. As result, the displacement and deformation values 
in several points were obtained. It is important to take into account that the displacement and deformation values can be experimentally obtained, measured in the actual structure or in a scale experimental model, or using a numerical model.

The final results will depend among others things on the quality of the numerical model (mesh, mechanical properties of the material, boundary conditions, etc.), the instrumentation used in the experimental measurements (LVDT - Linear Variable Differential Transformer or Displacement Indicator- mechanical or digital device), the availability of equipment, etc.

If there are suspicions that an area in the structure is damaged, the equipment density in the presumably damaged zone must be greater.

\section{Numerical Modeling}

The models used in this work are shown in Figs. (1-3), with their dimensions and applied loads. Fig. (1) corresponds to a simply supported beam; Fig. (2) a cantilever beam and Fig. (3) a bi-articulated frame. These 2D models, with rectangular elements of 4 nodes, were analyzed by the software (Algor 20) [17], considering a plane stress state. The change in local stiffness produced by the damage was modeled through a discrete crack which alters the design geometry, more specifically, the inertia moment of the affected area of the structure.

The material properties for the models show in Fig. (1) and (2) are: $E=1.910^{11}\left[\mathrm{~N} / \mathrm{m}^{2}\right] ; \mu=0.29$ and $\rho=7855$ $\left[\mathrm{Kg} / \mathrm{m}^{3}\right]$ corresponding to steel. As regards the bi-articulated frame, Fig. (3), the reinforced concrete properties are $\mathrm{E}=$ $2.0610^{10}\left[\mathrm{~N} / \mathrm{m}^{2}\right] ; \mu=0.15$ and $\rho=2405\left[\mathrm{Kg} / \mathrm{m}^{3}\right]$.

\section{Damage Detection}

A comparison of the vertical displacements values corresponding to the damaged and undamaged structures is done for the detection of the structural damage by using this variable as an index of damage.

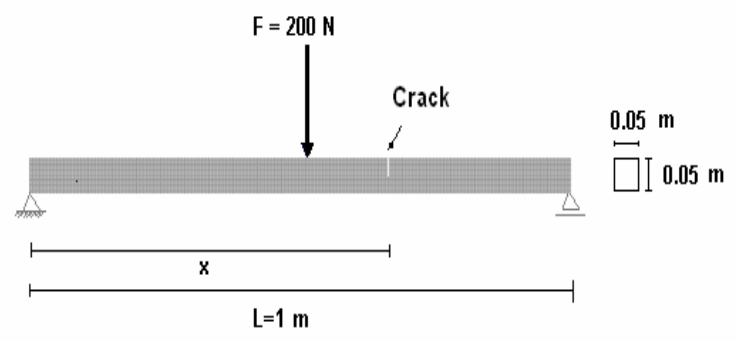

Fig. (1). Simply supported beam model.

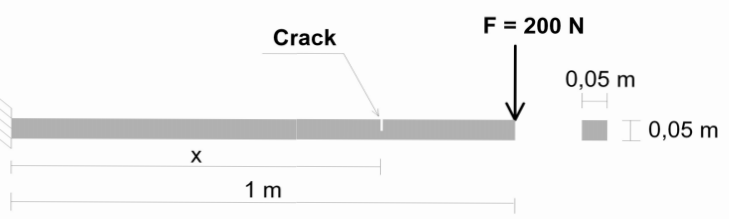

Fig. (2). Cantilever beam model.

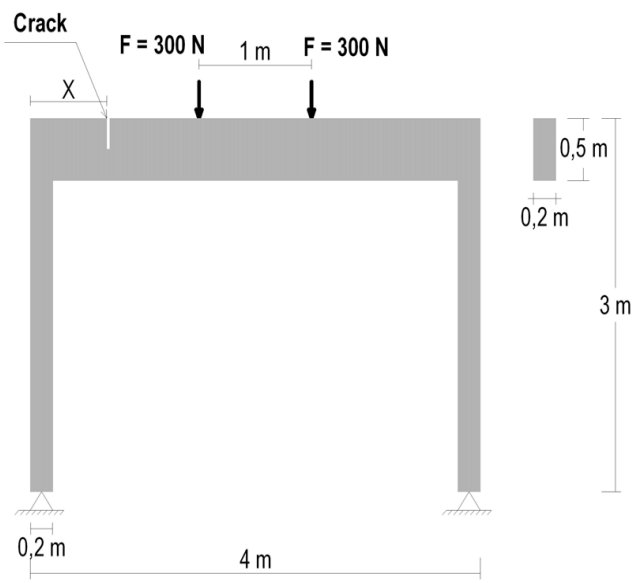

Fig. (3). Bi-articulated frame model.

\section{Analysis of the Results of Damage Detection a). Simply Supported Beam}

Fig. (4) shows the vertical displacements of a simply supported beam, as regards the relative location of each point, for different damages severity "a/h" (a = damage depth; $\mathrm{h}=$ total beam height) and damaged in location $\mathrm{x} / \mathrm{L}=$ 0.33 (where $\mathrm{x}$ is the coordinate of each point in the beam length direction and $\mathrm{L}$ is the total beam length). Furthermore, the curve corresponding to the vertical displacements of the undamaged structure has been included in this graph.

As it can be observed in it, the maximum displacement occurs in the central area of the beam, with a tendency towards the damaged area. Moreover, as the relation $\mathrm{a} / \mathrm{h}$ increases, i.e. when the severity of damage increases, the difference between the curves corresponding to the damaged and undamaged structure is greater.

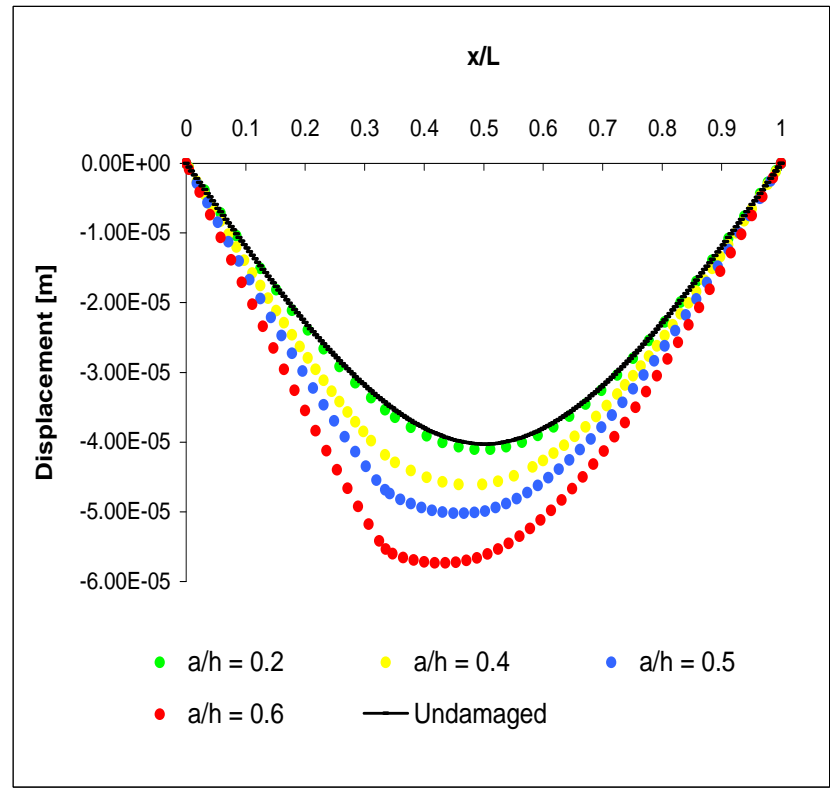

Fig. (4). Displacement of a supported beam with different levels of damage at $\mathrm{x} / \mathrm{L}=0.33$. 
Among the cases studied it can be seen that the curve corresponding to the relation $\mathrm{a} / \mathrm{h}=0.2$ differs slightly from that of the undamaged structure. This is the first limitation to this method since with the magnitude of the load applied there are not significant differences with the undamaged structure. A way of overcome this is by increasing the test load value (live load), so that the vertical displacements will also increase. However, from a practical point of view, this increase in the load is limited by structural safety and/or test costs.

In Fig. (5), the vertical displacements are represented as regards the relative location of each point for a damage severity $\mathrm{a} / \mathrm{h}=0.4$ and different damage location, i.e. different $\mathrm{x} / \mathrm{L}$ (same severity but different location). As it can be seen in this figure, when damage location coincides with the maximum vertical displacements area, there also is a maximum difference between the curves corresponding to the damaged and undamaged structures. It can also be seen here that the curve maximum tends towards the damaged area. It must be noticed that when the damaged is located near the support, the displacement curve does not present any important difference in relation to the undamaged structure. The method loses sensitivity as the damaged area is closer to the supports, similarly to what happens when the cracking depth is reduced. In these cases the value of the applied load should be increased but being careful not to overpass the service load of the most damaged area.

\section{b). Cantilever Beam}

The vertical displacement in a cantilever beam is shown in Fig. (6). It is damaged in a fixed position, in this case corresponding to $\mathrm{x} / \mathrm{L}=0.50$, for different relations of $\mathrm{a} / \mathrm{h}$. Furthermore, it has been included in the figure the curve corresponding to the undamaged structure. As it can be observed in this figure, the maximum displacement occurs at the free end of the beam. As the $\mathrm{a} / \mathrm{h}$ relation increases, i.e. when the damage is greater, the difference between the curves corresponding to the damaged and undamaged structures is greater.

Among the cases studied, it can be appreciated (Fig. (6)) that the curve corresponding to the relation $\mathrm{a} / \mathrm{h}=0.2$ differs

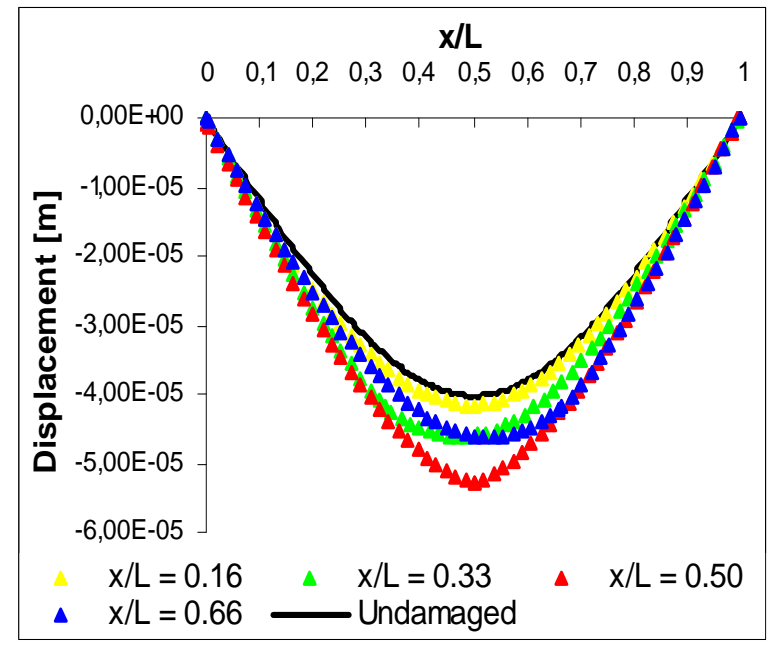

Fig. (5). Displacement of a supported beam with damage at different locations $(\mathrm{x} / \mathrm{L})$ and $\mathrm{a} / \mathrm{h}=0.4$.

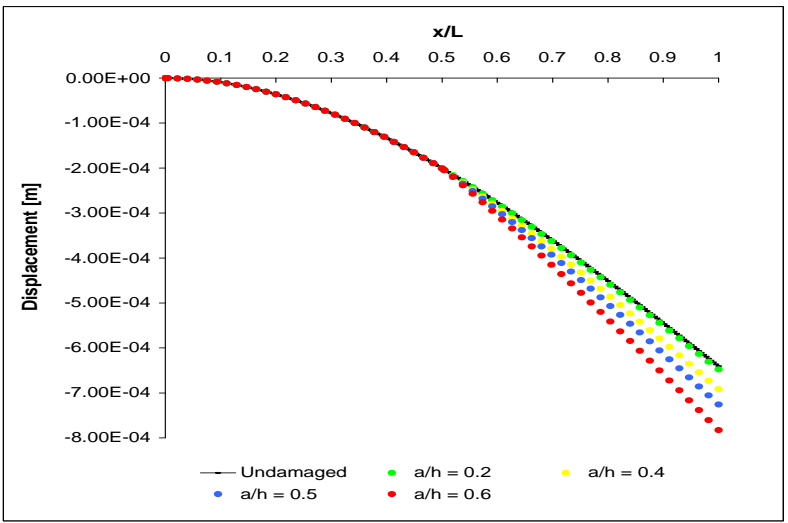

Fig. (6). Displacement of a cantilever beam with different levels of damage at $\mathrm{x} / \mathrm{L}=0.5$.

slightly from that of the undamaged structure. This is the first restriction of this method since with the magnitude of the load applied there are not considerable differences with de undamaged structure.

Fig. (7) shows the vertical displacements in relation to the relative location of each point in the beam for $\mathrm{a} / \mathrm{h}=0.4$. As it can be seen in the figure, when the damage is located near the clamped end, the vertical displacements curve presents the main differences as regards the undamaged structure. On the contrary, there are fewer differences when the damage is located near the free end. The method loses sensibility when the damaged area is near the free end of the cantilever beam.

\section{c). Bi-Articulated Frame}

Fig. (8) shows the displacement of a bi articulated frame lintel. The damage is located in the top of the lintel, in a fixed position, corresponding to $\mathrm{x} / \mathrm{L}=0.5$.

In the previous figure several $\mathrm{a} / \mathrm{h}$ relations are shown, where $\mathrm{a}$, is the damage depth and $\mathrm{h}$, is the lintel height. Besides, as in the previous cases, it has been included in the figure the curve corresponding to the vertical displacements of the undamaged structure, measured in the lower side of

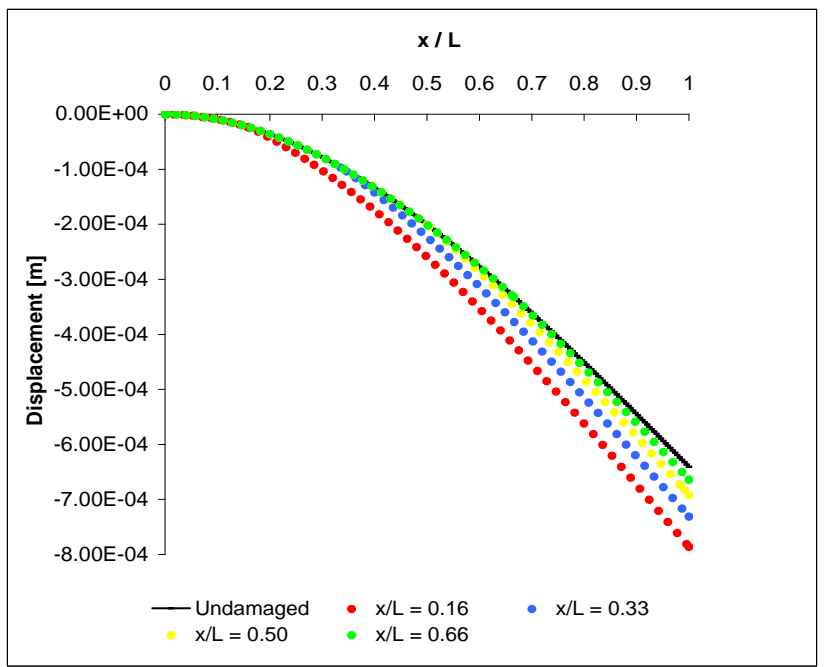

Fig. (7). Displacement of a cantilever beam with damage at different locations $(\mathrm{x} / \mathrm{L})$ and $\mathrm{a} / \mathrm{h}=0.4$. 


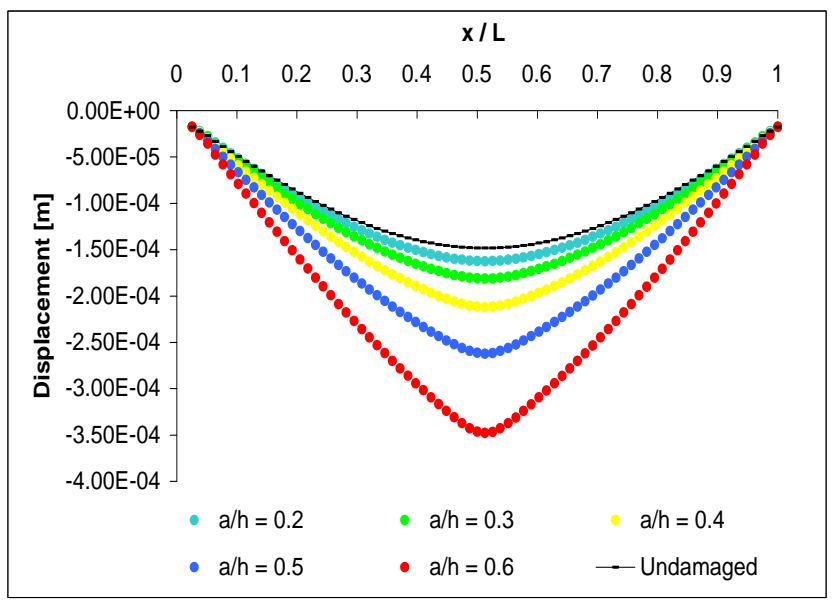

Fig. (8). Displacement of a bi articulated frame lintel with different damage degrees at $\mathrm{x} / \mathrm{L}=0.5$.

the frame lintel. The behavior observed here is similar to that of the simply supported beam.

In Fig. (9) are represented the vertical displacements in relation to the relative location of each point of the frame lintel, for a damage severity $\mathrm{a} / \mathrm{h}=0.5$ and different $\mathrm{x} / \mathrm{L}$ values.

Again, it can be observed here that the curve maximum moves towards the damaged area.

\section{Damage Localization}

Damage is located once its presence has been determined in the structure. Two methods are presented here:

- Vertical Displacements Variation Method

- Elastic Curvature Method

\section{Vertical Displacements Variation Method}

This method is based on the analysis of the graphics corresponding to the difference between the vertical displacements of the undamaged and damaged structure, for each point of it. This parameter is an index of its rigidity variation, and it is defined as:

$\delta_{i}=\left|y_{i D}-y_{i U D}\right|$

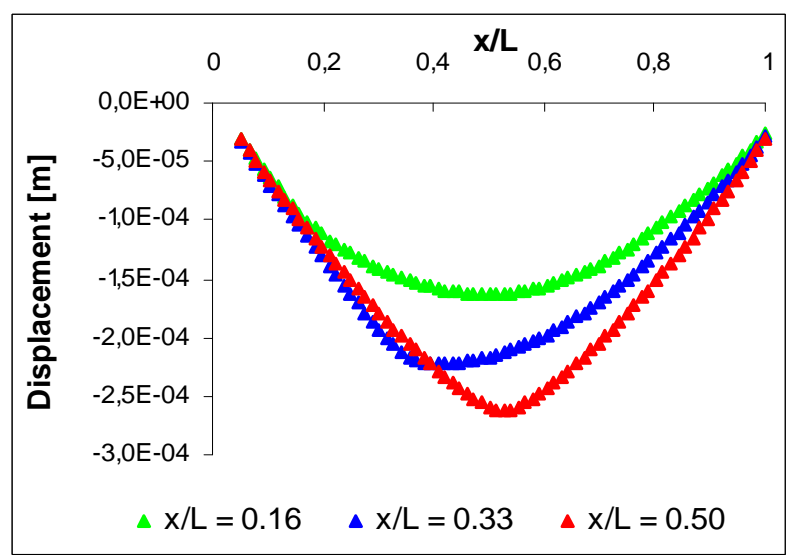

Fig. (9). Displacement of a bi articulated frame lintel with damaged at different locations $(\mathrm{x} / \mathrm{L})$ and $\mathrm{a} / \mathrm{h}=0.5$. where $y_{i D}$ represents the vertical displacement of the point $i$ in the damaged structure, and $y_{i U D}$ the vertical displacement of the same point but in the undamaged structure.

Damage location may be estimated if the density of measurements on the structure is adequate Taking into account the type of structure and the magnitude of damage.

\section{Analysis of the results with Vertical Displacement Varia- tion Method}

\section{a). Simply Supported Beam}

In Fig. (10) are represented the vertical displacements variation as regards the location of each point in the mesh for a simply supported beam, damaged in position corresponding to $\mathrm{x} / \mathrm{L}=0.16$, and two damaged severity $\mathrm{a} / \mathrm{h}=0.2$ and 0.5 . It can be seen here that in the place where the damage is located there is a gradient change in the vertical displacements variations and the curvature sign varies.

\section{b). Cantilever Beam}

In Fig. (11) are represented the variation of the vertical displacements for a cantilever beam in relation to the location of each point in the mesh, for a structure damaged in several places corresponding to $\mathrm{x} / \mathrm{L}=0.16 ; 0.33 ; 0.50$ and 0.66 , with a damage severity $\mathrm{a} / \mathrm{h}=0.5$.

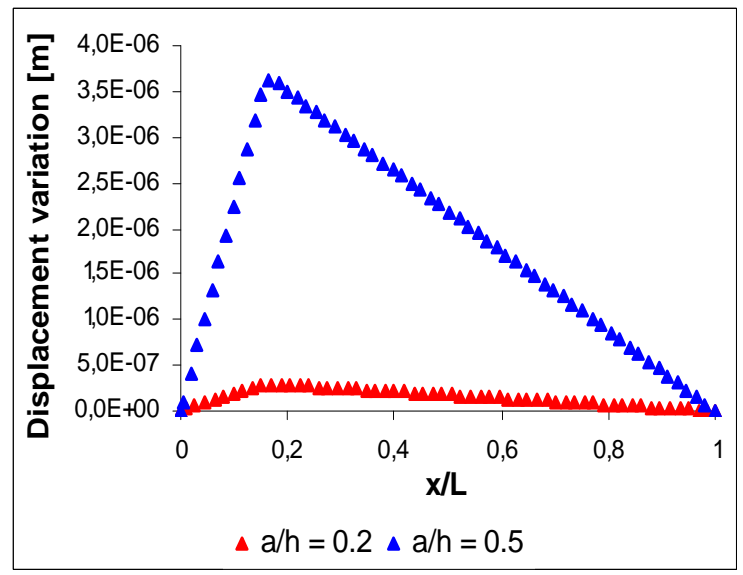

Fig. (10). Variation of the vertical displacements of a simply supported beam with damage at $\mathrm{x} / \mathrm{L}=0.16$.

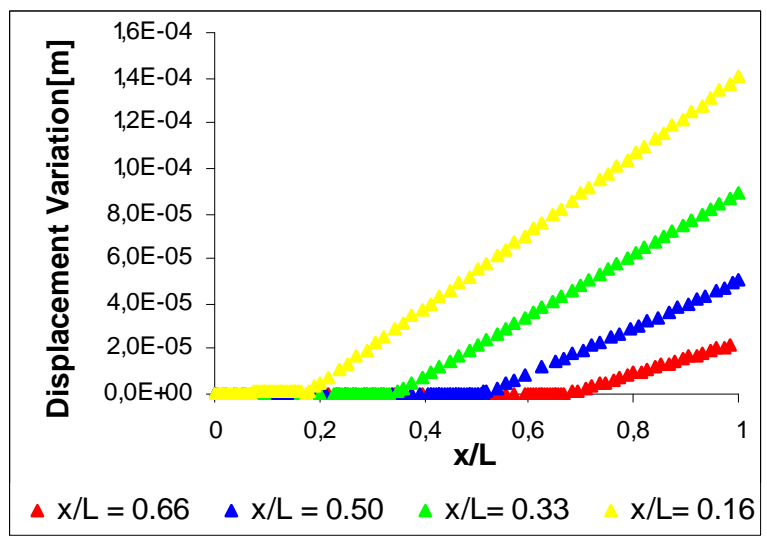

Fig. (11). Variation of the vertical displacements in cantilever beam with damage at different locations $(\mathrm{x} / \mathrm{L})$ and $\mathrm{a} / \mathrm{h}=0.5$. 
It can be appreciated Fig. (11) that up to the cracked zone, the difference between the vertical displacements value, for both damaged and undamaged beams, is approximately zero, whereas it increases from the location of the damage, where the gradient change in the curvature is produced.

\section{c). Bi-Articulated Frame}

Fig. (12) shows the variation of the vertical displacements for a bi-articulated frame in relation to the location of each point in the mesh, for structural damaged located in several places corresponding to the locations $\mathrm{x} / \mathrm{L}=0.16$; 0.33 ; and 0.50 , with a damage severity $\mathrm{a} / \mathrm{h}=0.5$.

It can be appreciated here that in the place where the damage is, there is a gradient change in the vertical displacements variations and consequently, the curvature sign varies.

\section{Elastic Curvature Method}

The displacement values obtained in certain points of the structure, through experimental measurement or, as they were obtained here, through numerical simulation, can be used to obtain the elastic curvature through an approximation of the Central Finite Differences. This way, the curvature is produced by [18]:

$\frac{d^{2} y}{d x^{2}}=\frac{y_{i+1}-2 y+y_{i-1}}{h^{2}}$

$i=2, \ldots ., n-1$

where $\mathrm{h}$ represents the distance between two adjacent points (step), whereas $\mathrm{y}$, represents the displacement in a determined point and $\mathrm{n}$ the number of points available in the mesh.

It is important to mention that this methodology is independent of the information of the undamaged structure. This is an advantage when this information is not available.

For an undamaged structure, the graphic of the elastic curvature represents a slight form. While a peak or a discontinuity in its form show an abnormal variation of the rigidity in that position, produced by its damage level.

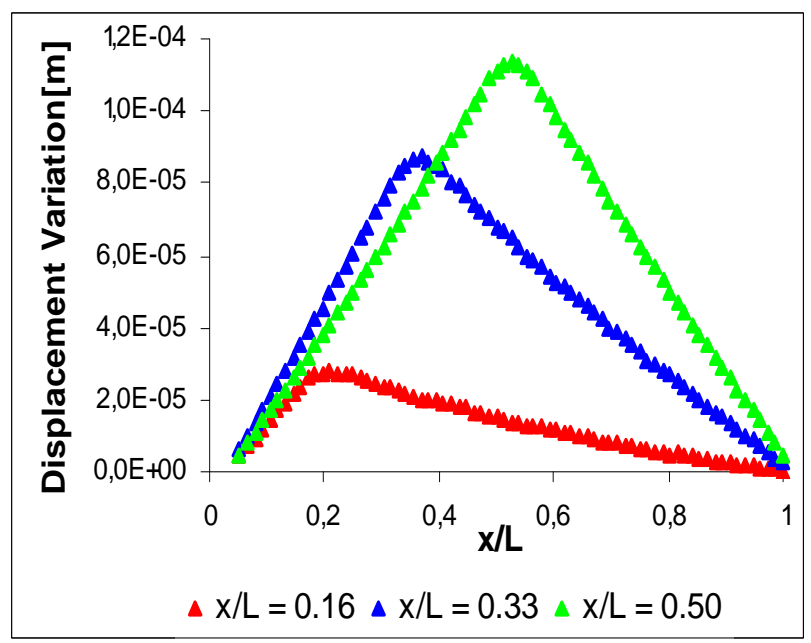

Fig. (12). Variation of the vertical displacements in a bi-articulated frame with damage at different locations $(\mathrm{x} / \mathrm{L})$ and $\mathrm{a} / \mathrm{h}=0.5$.

\section{Analysis of the results with Elastic Curvature Method}

\section{a). Simply Supported Beam}

Fig. (13) shows the elastic curvature, calculated according to equation (2), in relation to the location of each point in the mesh for a structure damaged in $\mathrm{x} / \mathrm{L}=0.33$, with a damage severity $\mathrm{a} / \mathrm{h}=0.5$. It can be appreciated here that the damaged area presents a pronounced variation. There are also three more variation points in a specific area where the load is applied, beam midpoint and in the places where the beam is supported. This variation can be minimized using a model with a refined mesh in those areas.

\section{b). Cantilever Beam}

The elastic curvature is shown in Fig. (14), in relation to the location of each point in the mesh for a cantilever beam with damage in the position corresponding to $\mathrm{x} / \mathrm{L}=0.5$ and with $\mathrm{a} / \mathrm{h}=0.5$. It can be appreciated here that the damaged area presents a pronounced variation, whereas the area where the load is applied (free end of the beam) it is observed only little disruption.

\section{c). Bi-Articulated Frame}

Fig. (15) shows the elastic curvature in relation to the location of each point in the mesh for a bi-articulated frame lintel subjected to the action of two punctual loads over the

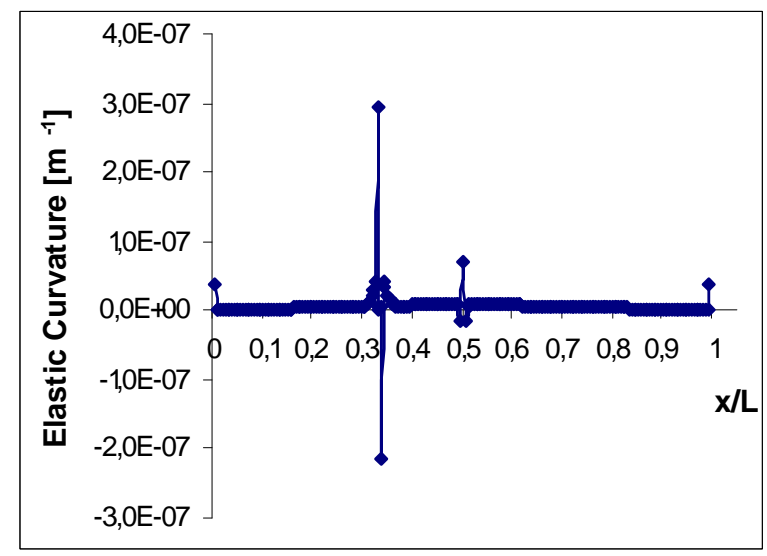

Fig. (13). Elastic curvature of a simply supported beam with damage at $\mathrm{x} / \mathrm{L}=0.33$ and $\mathrm{a} / \mathrm{h}=0.5$.

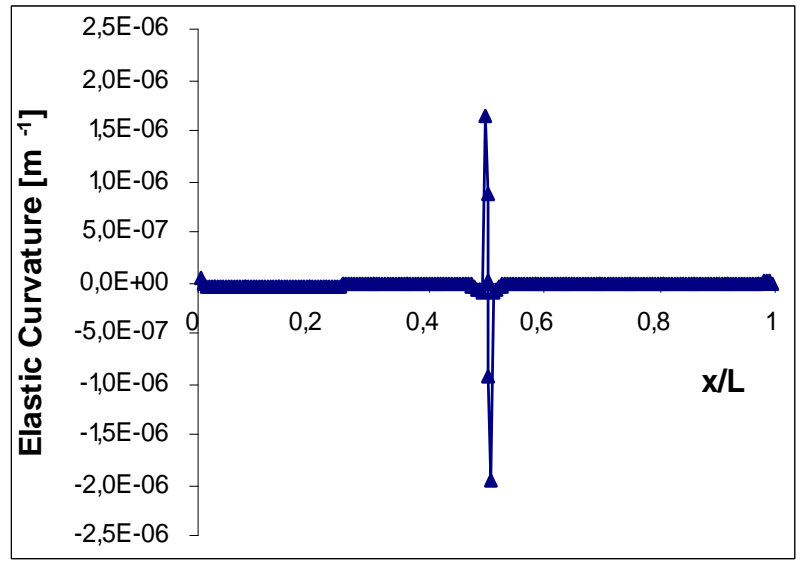

Fig. (14). Elastic curvature of a cantilever beam with damage at $x / L$ $=0.50$ and $\mathrm{a} / \mathrm{h}=0.5$. 


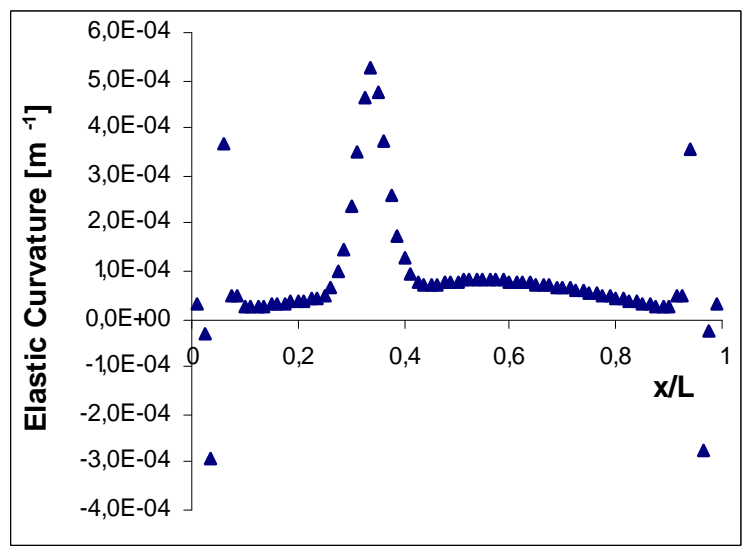

Fig. (15). Elastic curvature of a bi-articulated frame with damage at $\mathrm{x} / \mathrm{L}=0.33$ and $\mathrm{a} / \mathrm{h}=0.5$.

lintel Fig. (3) with damage on the upper area of the lintel in the position corresponding to $\mathrm{x} / \mathrm{L}=0.33$ and with $\mathrm{a} / \mathrm{h}=0.5$. The damaged area presents a pronounced variation. It can also be observed that in the column neighboring area there are important disruptions.

\section{Damage Quantification}

Once the damage has been located, the following step is to establish its magnitude. Although the damaged area may be seen, there is uncertainty as regards its magnitude in the interior of the structure. In order to cope with this, it is necessary to make a numerical model of the structure with the damage simulated in the location determined visually or using the techniques presented in section Damage localization or by the use of an experimental technique (for example, ultrasounds)

In this work, and with the purpose of quantifying the damage in the structure, models with different positions and degree of damage, are analyzed through a numerical method. As a consequence, graphics in 3 dimensions were obtained in relation to the following parameters: location, degree of damage, and a third factor related to the mechanical behavior of the damaged structure, for example, displacements or deformations. Then, entering in the graphic with damage position $\mathrm{x} / \mathrm{L}$ and Displacement measurement, the value of damage severity, a/h, can be obtained.

The mechanical parameters used in this paper were the Vertical Displacements, the Volumetric Displacements $(D V)$ as well as the Volumetric Deformation, with the purpose of finding out which of them is more sensitive to the damage severity. In relation to the last two parameters mentioned above, they take into account the variation of the displacements or strains throughout the structure. These parameters can be defined as the summation of the product of the vertical displacement $\left(y_{i}\right)$, or strain, produces in each point of the mesh by its influence volume $\left(V_{i}\right)[19]$ :

$$
D V=\sum_{i=1}^{n} y_{i} \times V_{i}
$$

They have the advantage of taking into account a greater volume of information, so that if there were measurement errors, they would have less impact.

\section{Analysis of the Damage Quantification \\ a). Simplv Supported Beam}

The values corresponding to the Volumetric Displacement, Volumetric Deformations [20] and Displacements in the middle point of the simply supported beam are shown in Table 1 in reference to the different relations used: $\mathrm{x} / \mathrm{L}$ (position) and $\mathrm{a} / \mathrm{h}$ (severity) worked out for a specific load applied in the middle point of the beam Fig. (1). Analyzing this, it can be concluded that the Vertical Displacements and the Volumetric Displacements represent a similar variation in percentage terms, in relation to the severities analyzed here, independently from the damage location. For this reason, it can be established here that, any of these parameters may be used. However, it may be more convenient to use Volumetric Displacements because for its determination more information are used, and so, a possible error in the experimental measurement may be quite attenuate. The vertical displacements used here are those used when locating the cracking.

Table 1. Midpoint Vertical Displacement, Volumetric Displacement and Volumetric Deformation of a Simply Supported Beam in Relation to its Location $(x / L)$ and Damage Degree $(a / h)$

\begin{tabular}{|c|c|c|c|c|c|c|c|c|c|}
\hline & \multicolumn{3}{|c|}{ Midpoint Vertical Displacement (m) } & \multicolumn{3}{|c|}{$\begin{array}{l}\text { Volumetric Displacement } \\
\qquad\left(\mathbf{m} \cdot \mathbf{m}^{3}\right)\end{array}$} & \multicolumn{3}{|c|}{$\begin{array}{l}\text { Volumetric Deformation } \\
\qquad\left(\mathbf{m} \cdot \mathbf{m}^{3}\right)\end{array}$} \\
\hline & \multicolumn{3}{|c|}{$\mathrm{x} / \mathrm{L}$} & \multicolumn{3}{|c|}{$\mathrm{x} / \mathrm{L}$} & \multicolumn{3}{|c|}{$\mathrm{x} / \mathrm{L}$} \\
\hline $\mathrm{a} / \mathrm{h}$ & 0.16 & 0.33 & 0.50 & 0.16 & 0.33 & 0.50 & 0.16 & 0.33 & 0.50 \\
\hline 0.75 & $5.26 \mathrm{E}^{-5}$ & $9.39 \mathrm{E}^{-5}$ & $1.59 \mathrm{E}^{-4}$ & $1.66 \mathrm{E}^{-6}$ & $2.84 \mathrm{E}^{-6}$ & $4.00 \mathrm{E}^{-6}$ & $7.74 \mathrm{E}^{-7}$ & $8.60 \mathrm{E}^{-7}$ & $9.80 \mathrm{E}^{-7}$ \\
\hline 0.60 & $4.39 \mathrm{E}^{-5}$ & $5.62 \mathrm{E}^{-5}$ & $7.55 \mathrm{E}^{-5}$ & $1.31 \mathrm{E}^{-6}$ & $1.49 \mathrm{E}^{-6}$ & $1.69 \mathrm{E}^{-6}$ & $7.31 \mathrm{E}^{-7}$ & $7.80 \mathrm{E}^{-7}$ & $8.49 \mathrm{E}^{-7}$ \\
\hline 0.40 & $4.16 \mathrm{E}^{-5}$ & $4.60 \mathrm{E}^{-5}$ & $5.31 \mathrm{E}^{-5}$ & $1.22 \mathrm{E}^{-6}$ & $1.35 \mathrm{E}^{-6}$ & $1.49 \mathrm{E}^{-6}$ & $7.09 \mathrm{E}^{-7}$ & $7.38 \mathrm{E}^{-7}$ & $7.78 \mathrm{E}^{-7}$ \\
\hline 0.33 & $4.11 \mathrm{E}^{-5}$ & $4.36 \mathrm{E}^{-5}$ & $4.78 \mathrm{E}^{-5}$ & $1.30 \mathrm{E}^{-6}$ & $1.28 \mathrm{E}^{-6}$ & $1.36 \mathrm{E}^{-6}$ & $7.02 \mathrm{E}^{-7}$ & $7.22 \mathrm{E}^{-7}$ & $7.55 \mathrm{E}^{-7}$ \\
\hline 0.20 & $4.05 \mathrm{E}^{-5}$ & $4.11 \mathrm{E}^{-5}$ & $4.21 \mathrm{E}^{-5}$ & $1.19 \mathrm{E}^{-6}$ & $1.20 \mathrm{E}^{-6}$ & $1.23 \mathrm{E}^{-6}$ & $6.91 \mathrm{E}^{-7}$ & $4.00 \mathrm{E}^{-7}$ & $7.17 \mathrm{E}^{-7}$ \\
\hline $\begin{array}{c}\text { Variation \% Min } \\
\text { - Max }\end{array}$ & 30 & 128 & 277 & 40 & 136 & 225 & 12 & 23 & 36 \\
\hline
\end{tabular}


The Volumetric Displacement is shown in Fig. (16) in relation to the damage parameters, damage location $(\mathrm{x} / \mathrm{L})$ and damage severity $(\mathrm{a} / \mathrm{h})$. Damage severity can be determined through this graphic, entering in it with the Volumetric Displacement and damage position $\mathrm{x} / \mathrm{L}$, in the same way as it was explained in section Damage quantification.

\section{b). Cantilever Beam}

The values corresponding to the Volumetric Displacement, Volumetric Deformations and Vertical displacements parameters in the free end of a cantilever beam are shown in Table 2 with reference to the different relations used: $\mathrm{x} / \mathrm{L}$ (position) and $\mathrm{a} / \mathrm{h}$ (severity). Analyzing this, it can be concluded that, as in the previous case, the Vertical displacements and the Volumetric Displacements present a similar variation in percentage terms, in relation to the severities analyzed here, independently from the damage location.

\section{c). Bi-Articulated Frame}

The values corresponding to the Volumetric Displacement, Volumetric Deformations and Vertical displacements parameters in the middle point of a bi-articulated frame lintel are shown in Table $\mathbf{3}$ in reference to the different relations used: $\mathrm{x} / \mathrm{L}$ (position) and $\mathrm{a} / \mathrm{h}$ (severity). It can be observed

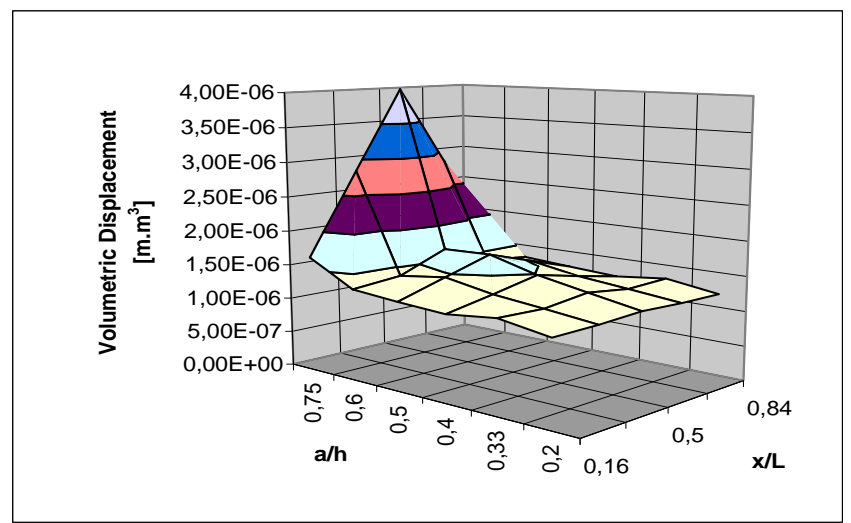

Fig. (16). Volumetric Displacement in relation to damage position and severity, for a simply supported beam.

here that the Volumetric Displacements present a higher variation in percentage terms than the other two parameters, independently from the damage location.

\section{EXPERIMENTAL MEASURES}

In order to validate the methodologies of detection and location of damage presented in this work, the experimental

Table 2. Free end Point Vertical Displacement, Volumetric Displacement and Volumetric Deformation of a Cantilever Beam in Relation to its Location $(x / L)$ and Damage Degree $(a / h)$

\begin{tabular}{|c|c|c|c|c|c|c|c|c|c|}
\hline & \multicolumn{3}{|c|}{ Free End Point Vertical Diplacement (m) } & \multicolumn{3}{|c|}{$\begin{array}{l}\text { Volumetric Displacement } \\
\qquad\left(\mathbf{m} \cdot \mathbf{m}^{3}\right)\end{array}$} & \multicolumn{3}{|c|}{$\begin{array}{l}\text { Volumetric Deformation } \\
\qquad\left(\mathbf{m} \cdot \mathbf{m}^{3}\right)\end{array}$} \\
\hline & \multicolumn{3}{|c|}{$\mathrm{x} / \mathrm{L}$} & \multicolumn{3}{|c|}{$\mathrm{x} / \mathrm{L}$} & \multicolumn{3}{|c|}{$\mathrm{x} / \mathrm{L}$} \\
\hline $\mathrm{a} / \mathrm{h}$ & 0.16 & 0.33 & 0.50 & 0.16 & 0.33 & 0.50 & 0.16 & 0.33 & 0.50 \\
\hline 0.75 & $2.00 \mathrm{E}^{-3}$ & $1.48 \mathrm{E}^{-3}$ & $1.11 \mathrm{E}^{-3}$ & $4.63 \mathrm{E}^{-5}$ & $2.98 \mathrm{E}^{-5}$ & $2.07 \mathrm{E}^{-5}$ & $1.19 \mathrm{E}^{-4}$ & $1.07 \mathrm{E}^{-4}$ & $1.03 \mathrm{E}^{-4}$ \\
\hline 0.50 & $8.82 \mathrm{E}^{-4}$ & $7.91 \mathrm{E}^{-4}$ & $7.26 \mathrm{E}^{-4}$ & $1.95 \mathrm{E}^{-5}$ & $1.66 \mathrm{E}^{-5}$ & $1.51 \mathrm{E}^{-5}$ & $9.77 \mathrm{E}^{-5}$ & $9.46 \mathrm{E}^{-5}$ & $9.15 \mathrm{E}^{-5}$ \\
\hline 0.40 & $7.86 \mathrm{E}^{-4}$ & $7.32 \mathrm{E}^{-4}$ & $6.91 \mathrm{E}^{-4}$ & $1.72 \mathrm{E}^{-5}$ & $1.55 \mathrm{E}^{-5}$ & $1.46 \mathrm{E}^{-5}$ & $9.44 \mathrm{E}^{-5}$ & $9.07 \mathrm{E}^{-5}$ & $8.94 \mathrm{E}^{-5}$ \\
\hline 0.33 & $7.25 \mathrm{E}^{-4}$ & $6.93 \mathrm{E}^{-4}$ & $6.70 \mathrm{E}^{-4}$ & $1.57 \mathrm{E}^{-5}$ & $1.47 \mathrm{E}^{-5}$ & $1.43 \mathrm{E}^{-5}$ & $9.14 \mathrm{E}^{-5}$ & $8.85 \mathrm{E}^{-5}$ & $8.77 \mathrm{E}^{-5}$ \\
\hline 0.20 & $6.67 \mathrm{E}^{-4}$ & $6.51 \mathrm{E}^{-4}$ & $6.47 \mathrm{E}^{-4}$ & $1.42 \mathrm{E}^{-5}$ & $1.41 \mathrm{E}^{-5}$ & $1.40 \mathrm{E}^{-5}$ & $8.68 \mathrm{E}^{-5}$ & $8.51 \mathrm{E}^{-5}$ & $8.49 \mathrm{E}^{-5}$ \\
\hline
\end{tabular}

Table 3. Midpoint Vertical Displacement, Volumetric Displacement and Volumetric Deformation of a bi Articulated Frame Lintel in Relation to its Location $(x / L)$ and Damage Degree $(\mathbf{a} / \mathbf{h})$

\begin{tabular}{|c|c|c|c|c|c|c|c|c|c|}
\hline \multirow[b]{3}{*}{$\mathrm{a} / \mathrm{h}$} & \multicolumn{3}{|c|}{ Midpoint Vertical Displacement (m) } & \multicolumn{3}{|c|}{$\begin{array}{l}\text { Volumetric Displacement } \\
\qquad\left(\mathbf{m} \cdot \mathrm{m}^{3}\right)\end{array}$} & \multicolumn{3}{|c|}{$\begin{array}{l}\text { Volumetric Deformation } \\
\qquad\left(\mathbf{m} . \mathrm{m}^{3}\right)\end{array}$} \\
\hline & \multicolumn{3}{|c|}{$\mathrm{x} / \mathrm{L}$} & \multicolumn{3}{|c|}{$\mathrm{x} / \mathrm{L}$} & \multicolumn{3}{|c|}{$\mathrm{x} / \mathrm{L}$} \\
\hline & 0.16 & 0.33 & 0.50 & 0.16 & 0.33 & 0.50 & 0.16 & 0.33 & 0.50 \\
\hline 0.60 & $1.54 \mathrm{E}^{-4}$ & $2.17 \mathrm{E}^{-4}$ & $2.86 \mathrm{E}^{-4}$ & $3.10 \mathrm{E}^{-4}$ & $6.16 \mathrm{E}^{-4}$ & $7.29 \mathrm{E}^{-4}$ & $2.92 \mathrm{E}^{-5}$ & $3.24 \mathrm{E}^{-5}$ & $3.34 \mathrm{E}^{-5}$ \\
\hline 0.50 & $1.47 \mathrm{E}^{-4}$ & $1.83 \mathrm{E}^{-4}$ & $2.23 \mathrm{E}^{-4}$ & $3.08 \mathrm{E}^{-4}$ & $4.59 \mathrm{E}^{-4}$ & $5.25 \mathrm{E}^{-4}$ & $2.82 \mathrm{E}^{-5}$ & $3.05 \mathrm{E}^{-5}$ & $3.11 \mathrm{E}^{-5}$ \\
\hline 0.33 & $1.40 \mathrm{E}^{-4}$ & $1.50 \mathrm{E}^{-4}$ & $1.62 \mathrm{E}^{-4}$ & $2.49 \mathrm{E}^{-4}$ & $3.03 \mathrm{E}^{-4}$ & $3.27 \mathrm{E}^{-4}$ & $2.67 \mathrm{E}^{-5}$ & $2.75 \mathrm{E}^{-5}$ & $2.77 \mathrm{E}^{-5}$ \\
\hline
\end{tabular}


results obtained from the test of a reinforced concrete beam are showed. This test was realized in the laboratory of Structural Models of the Engineering Department, Universidad Nac. del Sur.

Measurements of vertical displacements were realized, of a simply supported beam of section $8 \times 16 \mathrm{~cm}$ and $220 \mathrm{~cm}$ of length, with two top reinforcement $4.2 \mathrm{~mm}$ of diameter and two lower one $10 \mathrm{~mm}$ of diameter, stirrups of $6 \mathrm{~mm}$ of diameter were placed each $12 \mathrm{~cm}$. The typical compressive strength of the concrete used in the tested beam was $20 \mathrm{MPa}$.

The load was applied, at the center of the beam by means of a hydraulic press. The load was increased in steps, from 0 up to $7.07 \mathrm{kN}$ (ultimate load). As might be expected, with the load increases, the cracking increases.

The measurements of the vertical displacements were realized for the beam without damage and with different degrees of damage.

For the vertical displacements measurement ten Displacement Indicators were in use, separated by $15 \mathrm{~cm}$. In each step of load, the width and length of the cracks was measured up, using a $0.5 \mathrm{~mm}$ precision scale.

In Fig. (17 a) is shown a general view of the beam on the test bench and in b) the crack pattern of the beam tested.

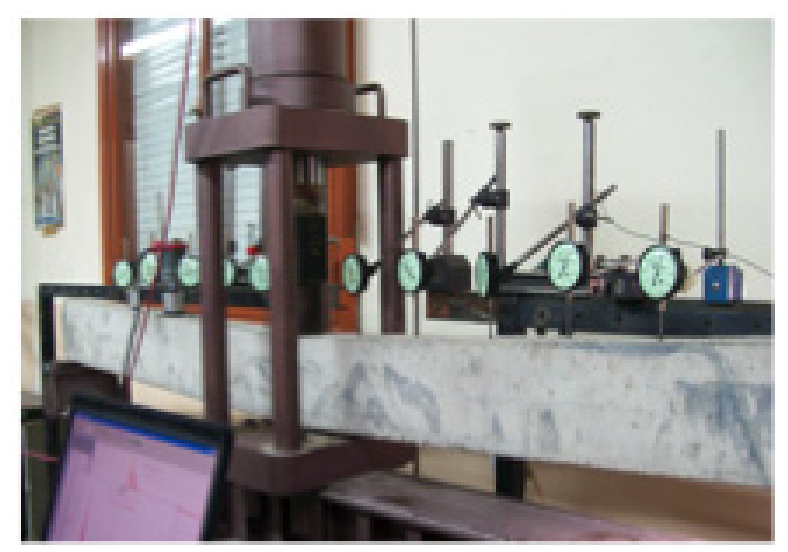

a). General view of the beam on the test bench

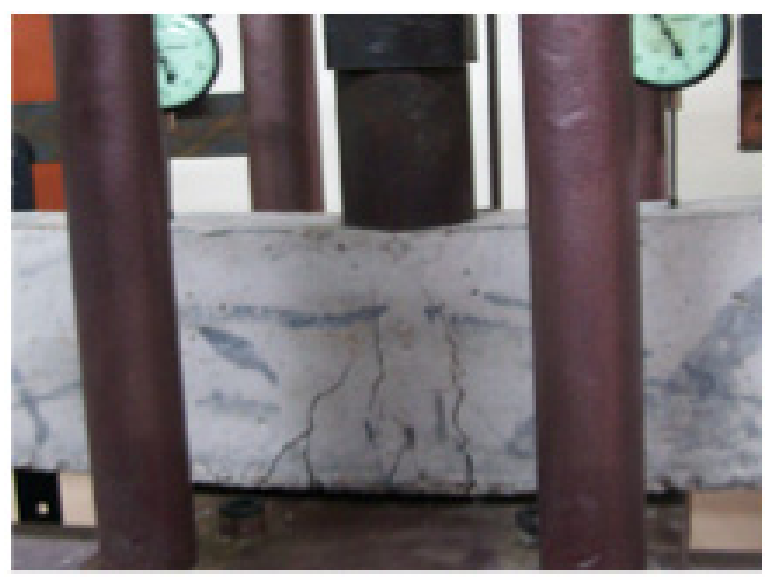

b). Crack pattern of the beam

Fig. (17). View of the beam tests.
In this work, with the vertical displacement measured experimentally, corresponding to $7000 \mathrm{Kg}$ applied load Fig. (18), the Displacement Variation was calculated and then these results were graphically displayed, Fig. (19). These figures show that although this beam presents distributed cracks, the technique presented here allows to detect damage and locate very clearly the affected area.

Fig. (20) represents the Elastic Curvature corresponding to $7.07 \mathrm{kN}$ applied load. Comparing Fig. (20) and (13), it can be seen that, in this case, more peaks appears due to the fissures distributed than those corresponding to the discrete fissure model, but they are easily detectable, with a density of measurements feasible at work, which is indicating that this methodology is reliable and of practical application.

Since the value of applied load of $2.57 \mathrm{kN}$ (when the bending cracks were visible), reveals variations similar to those presented in Figs. (18-20), as is expected, with lower values of the parameters represented.

It is to be noted that if it had been measured at point X / $\mathrm{L}=0.5$, probably the greatest values of the three parameters analyzed would correspond to this point. However, the maximums are at the point of measuring $\mathrm{X} / \mathrm{L}=0.4$, coinciding with the trend in the cracking pattern of the beam, which presents an asymmetry towards this point.

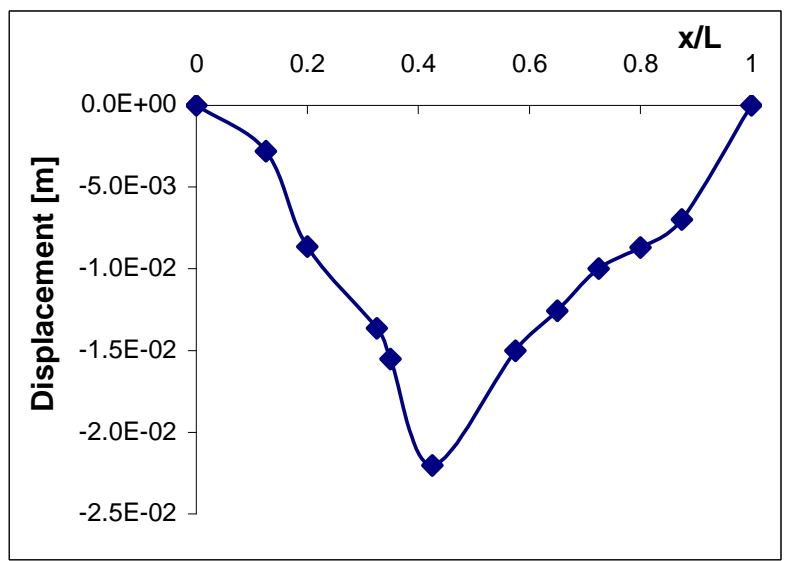

Fig. (18). Displacement for the crack pattern corresponding to 7.07 $\mathrm{kN}$ applied load.

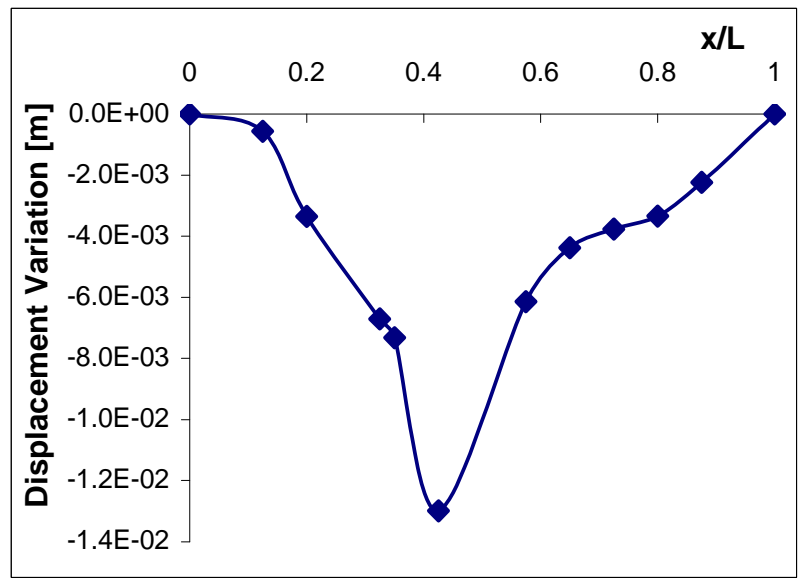

Fig. (19). Displacement Variation for the crack pattern corresponding to $7.07 \mathrm{kN}$ applied load. 


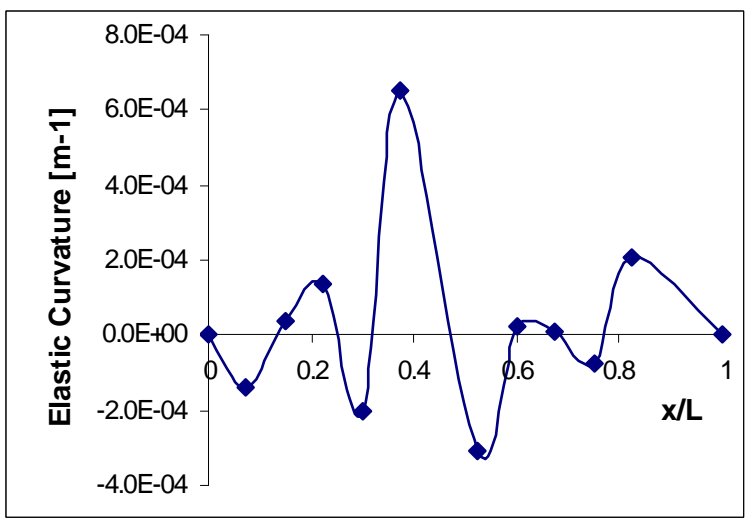

Fig. (20). Elastic Curvature for the crack pattern corresponding to $7.07 \mathrm{kN}$ applied load.

\section{CONCLUSIONS}

The technique presented here may be an important tool which may be used when studying pathologies in structures as it allows determining damage detection, its localization and quantification, as well as monitoring its progress in a reinforced concrete or metallic structure as time goes by in order to detect the right time for its repair.

Numerical models of analysis are combined with experimental measurements (displacements and deformations) which do not affect the structural integrity for the application of this technique, so that it is considered a non destructive analysis technique. The reliability of the result depends on the quality of the vertical displacements measurements realized in situ.

\section{ACKNOWLEDGEMENTS}

The authors want to thank the Engineering Department as well as to the Science and Technology Department of the Universidad Nacional del Sur, for the support given for the development of these investigations.

\section{Notation}

$\begin{array}{ll}\mathrm{a} & =\text { Damage depth } \\ \mathrm{E} & =\text { Young's Modulus } \\ \mathrm{h} & =\text { Total beam height } \\ \mathrm{L} & =\text { Total beam length } \\ \mathrm{x}, \mathrm{y} & =\text { Cartesian coordinates in two-dimensional space } \\ \mathrm{yi}_{\mathrm{D}} & =\text { Damage structure displacement of point } \mathrm{i} \\ \mathrm{yi} & =\text { Undamaged structure displacement of point } \mathrm{i} \\ \delta \mathrm{i} & =\text { Displacement variation method parameter } \\ \mu & =\text { Poisson's ratio } \\ \rho & =\text { Mass density of the material }\end{array}$

\section{REFERENCES}

[1] P. Rizos, N. Aspragathos and A. Dimarogas, "Identification of crack location and magnitude in a cantilever beam from the vibration modes", Journal of Sound and Vibration, vol. 138(3), pp. 381$388,1990$.

[2] A. Dimarogas, "Vibration of cracked structures: a state of the art review", Engineering Fracture Mechanics, vol. 55(5), pp. 831-857, 1996.

[3] O. Salawu, "Detection of structural damage through changes in frequency: a review article", Engineering Structures, vol. 19(9), pp.718-723, 1997.

[4] X. Yang, S. Swamidas and R. Seshadri, "Crack identification in vibrating beams using the energy method", Journal of Sound and Vibration, vol. 244(2), pp.339-357, 2001.

[5] J. Kim and N. Stubbs, "Crack detection in beam - type structures using frequency data", Journal of Sound and Vibration, vol. 259 (1), pp. 145-160, 2003.

[6] G. Owolabi, A. Swamidas and R. Seshadri, "Crack detection in beams using changes in frequencies and amplitudes of frequency response functions", Journal of Sound and Vibration, vol. 256, pp. $1-22,2003$.

[7] Z. Zembaty, M. Kowalski and S. Pospisil, "Dynamic identification of a reinforced concrete frame in progressive states of damage", Engineering Structures, vol. 28, pp. 668-681, 2006.

[8] N. F. Ortega and S. I. Robles, "Modelo Numérico para Predecir la Vida Residual de Vigas de Hormigón, con sus Armaduras Afectadas por la Corrosión", in Proceedings of $16^{\circ}$ Reunión Técnica de la Asociación Argentina de Tecnología del Hormigón, pp. 299-307, 2006.

[9] J. Chou and J. Ghaboussi, "Genetic algorithm in structural damage detection", Computers \& Structures, vol. 79, 1335-1353, 2001.

[10] Choi, Jun S. Leea, E. Choia and H. N. Cho "Development of elastic damage load theorem for damage detection in statically determinate beam", Computers \& Structures, vol. 82, pp. 2483-2492, 2004.

[11] D. Maity and A. Saha, "Damage assessment in structures from changes in static parameter using neural networks", Sādhanā, vol. 29(3), pp. 315-327, 2004.

[12] S. Suresh, R. Ganguli, V. Mani and S. N. Omkar. "Identification of crack location and depth in a cantilever beam using a modular neural network approach", Smart Materials and Structures, vol. 13, pp. 907-915, 2004.

[13] T. Sain Chandra and J.M. Kishen, "Damage and residual life assessment of structures using fracture mechanics", in Proceedings of. 16th ASCE Engineering Mechanics Conference, 2003.

[14] S. Caddemi and A. Morassi, "A Proceeding for multiple damage identification in elastic beams", in Proceedings of World Congress on Structural and Multidisciplinary Optimization, 2005.

[15] F. Jiang, R. Aashish, K. S. Vecchio, R. R. Adharapurapu. "Crack length calculation for bend specimens under static and dynamic loading", Engineering Fracture Mechanics, vol. 71, pp. 1971-1985, 2004.

[16] S. Caddemi and A. Morassi, "Crack detection in elastic beams by static measurements", International Journal of Solids and Structures, vol. 44, pp. 5301-5315, 2007.

[17] "Algor120 Professional Mech/VE, Docutech, Linear Stress and Dynamics, Reference Division.” Pittsburgh, Pennsylvania, 2007.

[18] Q. Lu, G. Ren and Y. Zhao, "Multiple damage location with flexibility curvature and relative frequency change for beam structure", Journal of Sound and Vibration, vol. 253(5), pp.1101-1114, 2002.

[19] N. F. Ortega and J. V. Arias, "Comparison of mechanical efficiency between an Hyperbolic Parabolic and a experimental model", in Proceedings of IV World Congress on Computational Mechanics, 1998.

[20] S. I. Robles and N. F. Ortega, "Study of Volumetric Displacements of shells", Journal of the International Association for Shell and Spatial Structures, vol. 42(137), pp. 139-147, 2001. 